\title{
Investigating the Groundwater Occurrence in Wadi Rahjan and Its Potential Contribution to Ain Zubaida Using Magnetic and Electric Methods, Makkah Al-Mukarramah, KSA
}

\author{
Mansour Abdullah Al-Garni \\ Department of Geophysics, Faculty of Earth Sciences, King Abdulaziz \\ University, P.O. 80206, Jeddah, Saudi Arabia \\ maalgarni@kau.edu.sa
}

Received: 23/10/2005

Accepted: 12/3/2006

Abstract. Ground magnetic and DC resistivity surveys are implemented to explore groundwater in the northern part of Wadi Rahjan, Makkah Al-Mukarramah, Saudi Arabia. This part includes the downstream area of Wadi Rahjan which flows into Wadi Nu'man where Ain Zubida is located. A system of E-W dikes is shown on available geologic map, which is cutting across the surrounding metavolcanic rocks and Wadi Rahjan stream. This study aims to locating the extensions of these dikes/discontinuities that may control the groundwater flow and distribution along this important part of Wadi Rahjan.

Ground magnetic survey is utilized along wadi Rahjan and the magnetic data are presented as contour map. Selected nine profiles are quantitatively analyzed using analytic signal analysis and horizontal gradient techniques. The present study reveals four discontinuities representing most probably dikes crossing the wadi. These dikes have great impact on the groundwater flow from upstream side to downstream side reaching wadi Nu'man where these dikes act as barriers for groundwater flow.

Electrical resistivity sounding using Schlumberger array is used along the wadi to delineate the extent of saturation zones, depth to basement, and to clarify the possible occurrence of the groundwater accumulations. It can be used also to show the effect of dikes occurrence on the groundwater flow and its distribution along this part of the Wadi. The study was successful in locating the water saturated zone and in determining its extension along the downstream part at the south of a major dike that partially prevents the groundwater flow to wadi Nu'man. 


\section{Introduction}

Wadi Rahjan lies between longitudes $40^{\circ} 01^{\prime}-40^{\circ} 05^{\prime} \mathrm{E}$ and latitudes $21^{\circ} 15^{\prime}-$ $21^{\circ} 17^{\prime} \mathrm{N}$ and is located about $30 \mathrm{~km}$ to the southeast of Makkah AlMukarramah city (Fig. 1). It is extended from the NW to SE direction for about $5 \mathrm{~km}$. It is considered as one of the main water resource for Wadi Nu'man, where Ain Zubida is located. Ain Zubida is considered as one of the oldest and most famous Ains in the Arabian Peninsula. It is 1200 years old (Al-Makki, 1992), and is believed to be originated from Jabal Kara in Taif, streaming through a certain prepared tunnel that extends along Wadi Nu'man supplying the Holy areas (Arafat, Muzdalifah and Mena).

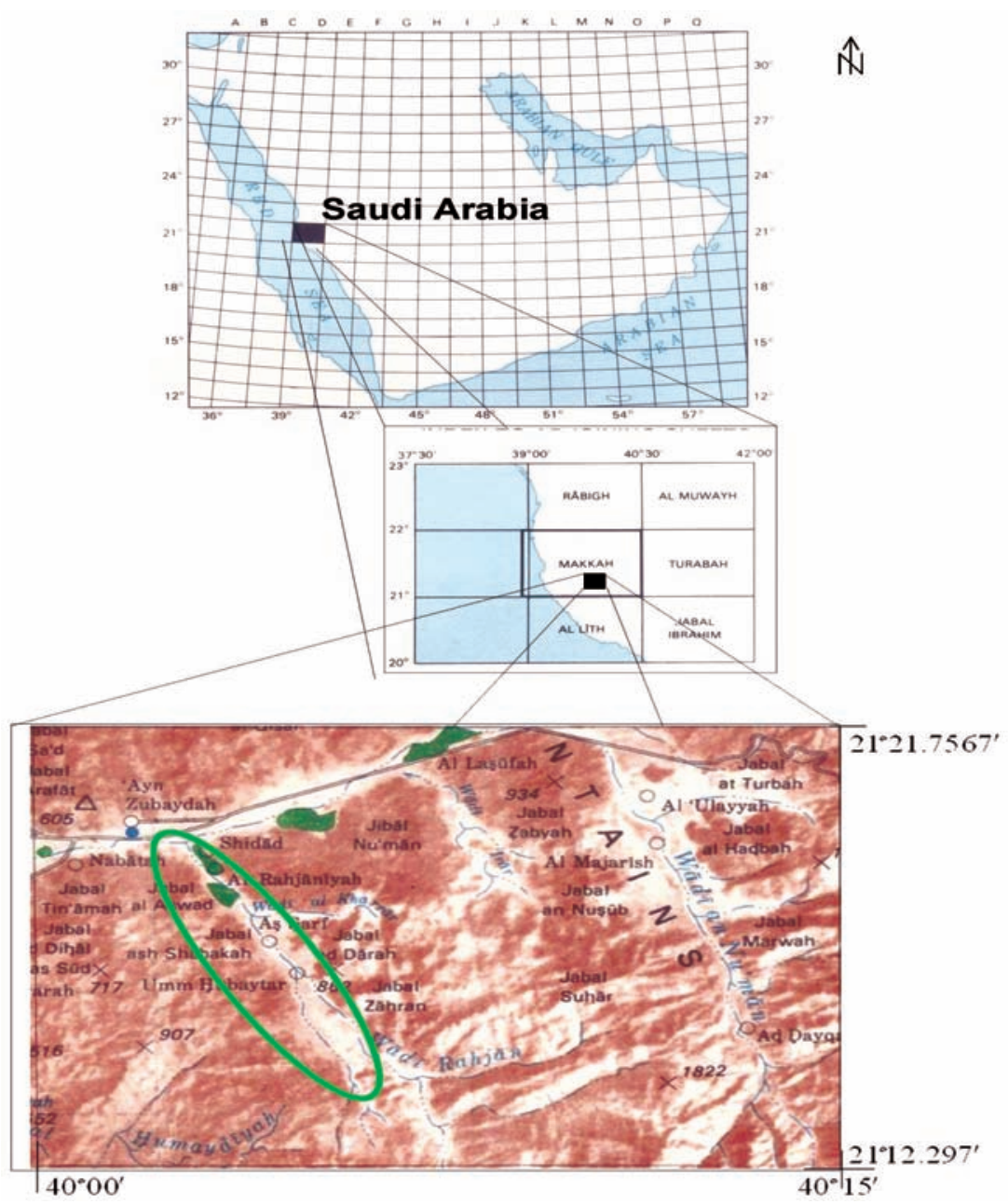

Fig. 1. Location map of the study area within Makkah Quadrangle. 
Wadi Rahjan area is located on the rifted western margin of the Arabian Shield and is considered as a part of the Nu'man batholith of Precambrian age. The Nu'man batholith is mainly composed of monzogranite and containes synclinal keels, rafts, roof pendants and screens of late Precambrian rocks that are predominantly metamorphosed lavas and volcano-clastic rocks ranging in composition from basalt to rhyolite (Moore and Al-Rehaili, 1989)

Figure 2 presents a geological map of Wadi Rahjan area showing three geologic complexes: Nu'man complex, Shamiyah complex and Milh complex (Moore and Al-Rehaili, 1989). Nu'man complex, which covers the southeastern part of Wadi Rahjan area, mainly consists of massive to foliated biotite monzogranite, gneisses in places with minor granodiorite; Shamiyah complex outcrops at the northwestern part of the area, mainly consists of tonalite of granodiorite monzogranite; and Milh complex occupies the area between Nu'man and Shamiyah complexes at the western part of Wadi Rahjan, mainly consists of diorite to quartz-diorite with minor grano-diorite in some places (Smith, 1980).

The area of Wadi Rahjan is located in a well-defined zone of foliation or cataclastics or both. The Nu'man structural zone is about $55 \mathrm{~km}$ long and paralleled for much of its length by a wide dike of pegmatite to spherulitic rhyolite. The Ad-Damm fault bounds Wadi Rahjan from south and extends northeast toward Al-Hada mountain. In the area of Wadi Rahjan, there are five dikes striking approximately E-W, which are well-developed in the Milh complex at the western side of the wadi (Fig. 2). These dikes infill faults in some places and are typically long.

Wadi Rahjan itself is covered by the alluvial fan Quaternary deposits. The deposits consist of sand and gravel and attain an average thickness of 20-30 m and these deposits are observed in the Nu'man drainage systems (Moore and AlRehaili, 1989).

Magnetic and Schlumberger sounding methods are utilized in this study because they are fast, cover a large area within a short period of time, not costly as seismic method and for their ability to delineate the geological structure and saturated zone, which are the main objective of the present study. Magnetic survey was extensively conducted across and along profiles, depending on the accessibility, in that wadi. A total magnetic intensity map is constructed from the collected data and subjected to some analysis, such as identifying different magnetic zones and lineaments. Based on the total magnetic field intensity map, nine profiles are chosen to be quantitatively investigated in order to delineate the most probable structural trends affecting this part of Wadi Rahjan. This detailed magnetic survey also provides approximately the subsurface configuration of the 


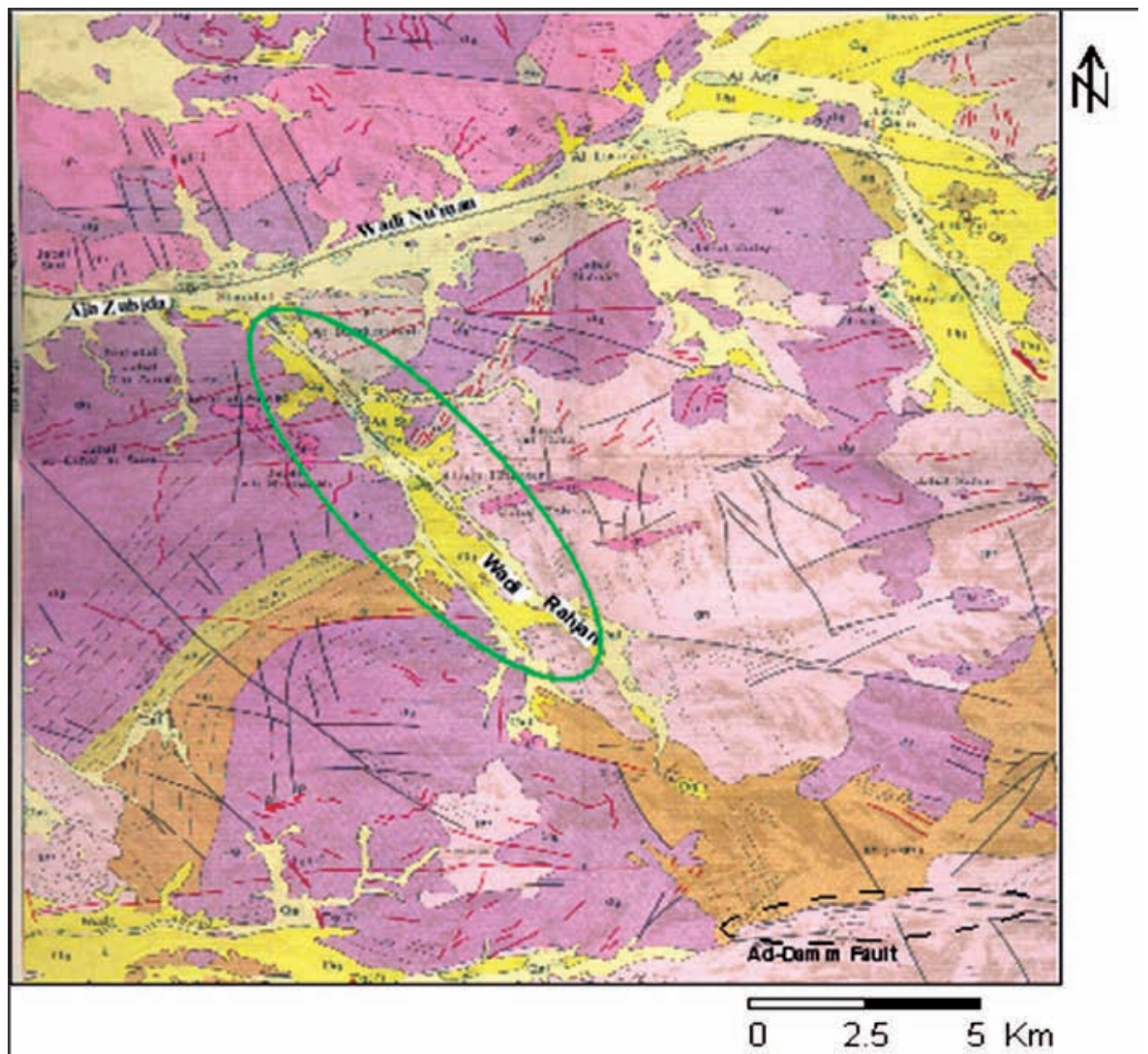

aq

as

ag

Oal Unconsolidated deposits_mainly wadi sand and gravel subordinate wind-blow sand

Og

dl $\mathrm{dg}$ do

Conglomerate-Unconsolidated, pebble to coarse boulder, subordinate partly consolidated pebbly sandstone

DIORITE, GABBRO, NORITE - Subsidiary quartz diorite, ultra- basic rock, local olivine gabbro (do). Intrusions with primary layering (dl), without primary layering (dg). Foliation in places

gn gk gt NU'MAN MONZOGRANITE - Mainly coarse-grained, biotite hearing with minor hornblende. (+gf) gk gt Local gradation to syeno granite. Arcuate body (qk), granodiorite (gr); foliated in places (qf)

CONTACT - Dashed where approximately located

Dike

Fig. 2. Geologic map of Wadi Rahjan and its surroundings (Smith, 1980). 
basement rock surface. Fourteen vertical electrical soundings, using Schlumberger array, are conducted along a profile taken along wadi Rahjan. These vertical electrical soundings were successful in delineating the groundwater occurrences and their relation to the geological structures that might be affecting the wadi.

\section{Geophysical Survey and Data Presentation}

\section{Detailed Ground Magnetic Survey}

According to the geology of Wadi Rahjan, this area is covered by different types of lithological units with different subsurface structural features, faults, fractures, and dikes. Each of these lithological units and structures has distinctive effects on the total magnetic field. Therefore, they are considered as targets of magnetic survey.

The total magnetic intensity field survey was conducted along 20 profiles extending from northeast-southwest across the Wadi Rahjan strike and a profile extending along the wadi northwest-southeast, depending on the accessibility of the study area. The proton precision magnetometer model Envi-Mag, Scintrex, Canada, was used in this survey. This is a portable magnetometer that can be also used as a "base station" magnetometer; its accuracy is $0.1 \mathrm{nT}$.

A total of more than 2150 magnetic readings were measured with $5-10 \mathrm{~m}$ station interval depending on the field condition. Two proton precision magnetometers were used in which one was used as a base station and the other was used for measuring the total field intensity. A mesh-like was designed to conduct measurements with station interval ranging between 5 to $10 \mathrm{~m}$ along the NE-SW profiles and $50 \mathrm{~m}$ or less along NW-SE profile depending on the acceptability and on the observations on both sides of wadi Rahjan. The locations of the collected ground magnetic data in Wadi Rahjan are shown in Fig. 3.

The magnetic field data were investigated carefully and subjected to corrections such as diurnal variation and the effects of micro-pulsation (effects due to fences, bridges, pipelines and tanks etc.). The micro-pulsation is recognized as outliers and should be eliminated. Figure 4 shows the total magnetic intensity contour map that has been constructed from the magnetic observations. Furthermore, nine profiles are selected across and along the wadi in order to study quantitatively the structure that might be presented in that wadi (Fig. 4).

\section{Vertical Electrical Soundings}

The vertical electrical sounding survey (VES) was conducted using the Schlumberger array at 14 sites distributed along Wadi Rahjan strike from southeast to northwest (Fig. 3). For each VES, data were collected at seven measure- 


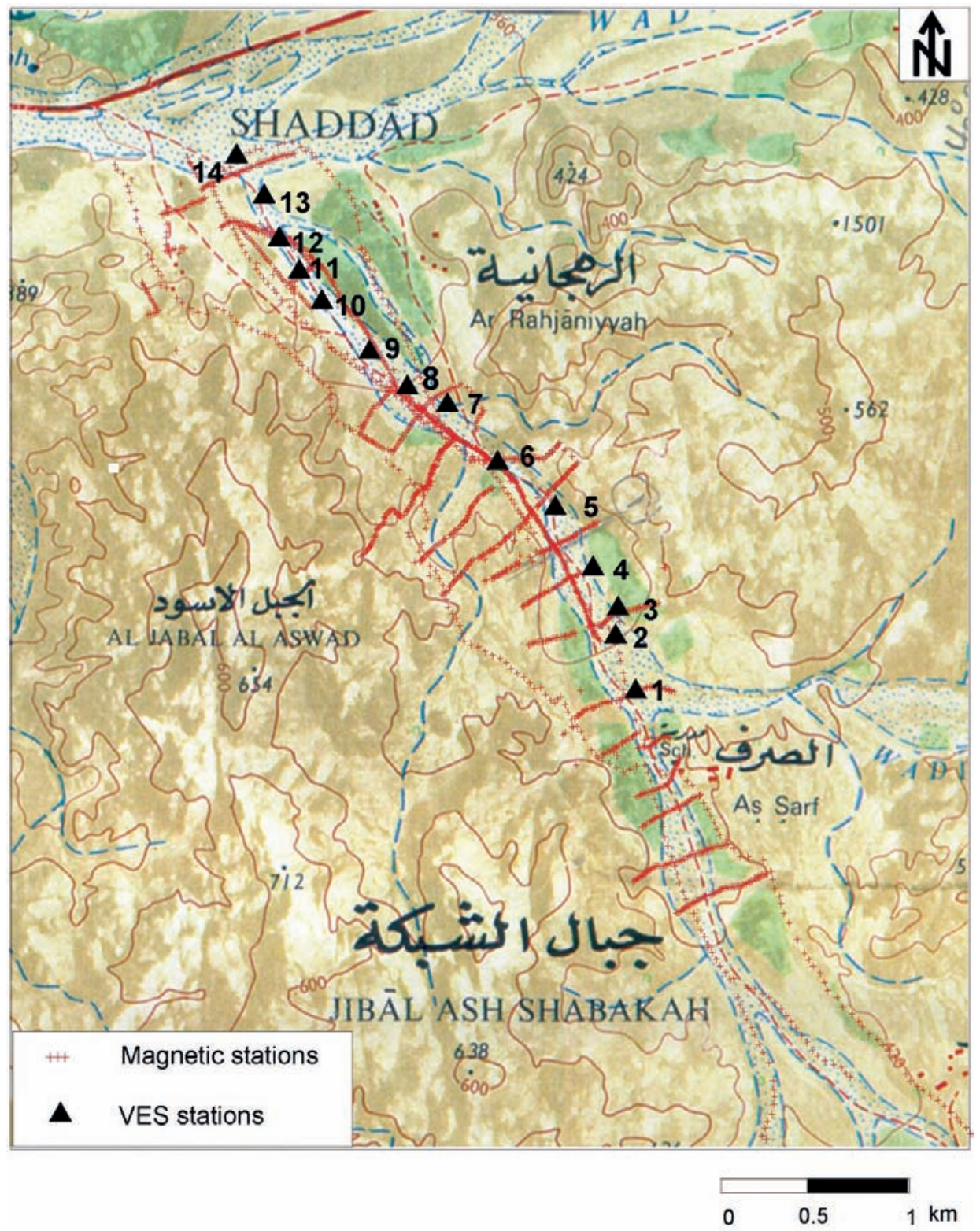

Fig. 3. Locations of the collected magnetic data and vertical electrical sounding stations. 


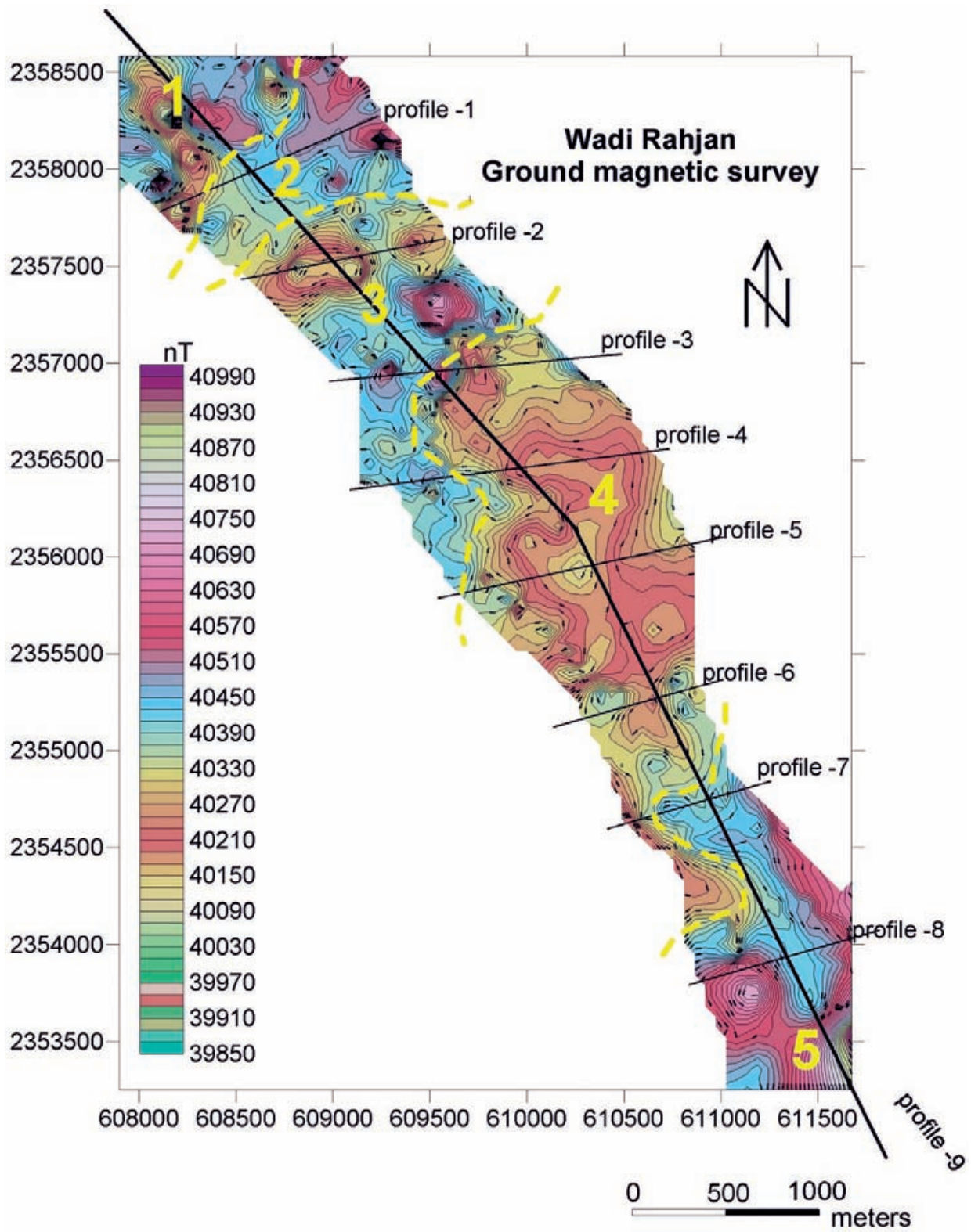

Fig. 4. Contour map of the total magnetic field intensity of wadi Rahjan showing the classified five zones and the selected nine profiles. 
ments per decade in order to obtain reasonable data continuity. The maximum distance of half current electrode spacing $(\mathrm{AB} / 2)$ is $200 \mathrm{~m}$. These measurements associated with the expansion of current electrodes provided a considerable depth penetration beneath each sounding site. The equipment that has been used in this survey was a modern 1200 Watts D.C. resistivity-meter, model ELREC-T (IRIS-instruments, France).

The collected field measurements (Fig. 5) for each vertical electrical sounding curve was first compiled to describe the apparent resistivity $\left(\rho_{\mathrm{a}}\right)$ from its different segments. The continuous sounding curve was then smoothed and digitized to produce six $\left(\rho_{\mathrm{a}}\right)$ readings per decade at half the electrode spacing.

\section{Geophysical Data Processing}

\section{Magnetic Data Processing}

The total magnetic field intensity map shows that Wadi Rahjan can be classified to five zones (Fig. 4). These zones have different average total magnetic intensity and magnetic anomalies frequency. Image map (Fig. 6) analysis shows that high magnetic anomalies are observed at the north eastern corner of the Wadi Rahjan. The total magnetic field intensity map is subjected to further representation using shaded relief (raster) map (Fig. 6). The analysis of this map shows that high magnetic anomalies are observed at the north eastern corner of Wadi Rahjan. This map use colors to indicate the local orientation of the surface relative to the direction of a user-defined light source. In this case, the light source can be considered as the sun shining on a topographic surface where portions of the surface that face away from the light toward the viewers and thus appear darker. This representation is very valuable in enhancing the magnetic features where the magnetic contacts are plotted as lineaments (Fig. 6). Thus, the lineaments are used to construct a rose diagram showing the distribution of these lineaments (Fig. 6). The major trend of these lineaments is NW-SE.

The most important goal of data processing is mainly to simplify the complex information that is provided in the original data. Selected nine profiles are taken along some magnetic features from the constructed total magnetic intensity map (Fig. 4). These profiles are subjected mainly to two transformations in order to detect surface and subsurface variations of magnetic characters of the rocks comprising Wadi Rahjan.

The selected profiles of total magnetic intensity field are subjected to analytic signal and horizontal gradient filters (Fig. 7). The theory behind the analytic signal is given by Nabighian (1972) and the horizontal gradient is given by Gunn (1975). Nabighian (1972) defined the analytic signal as a complex field deriving 

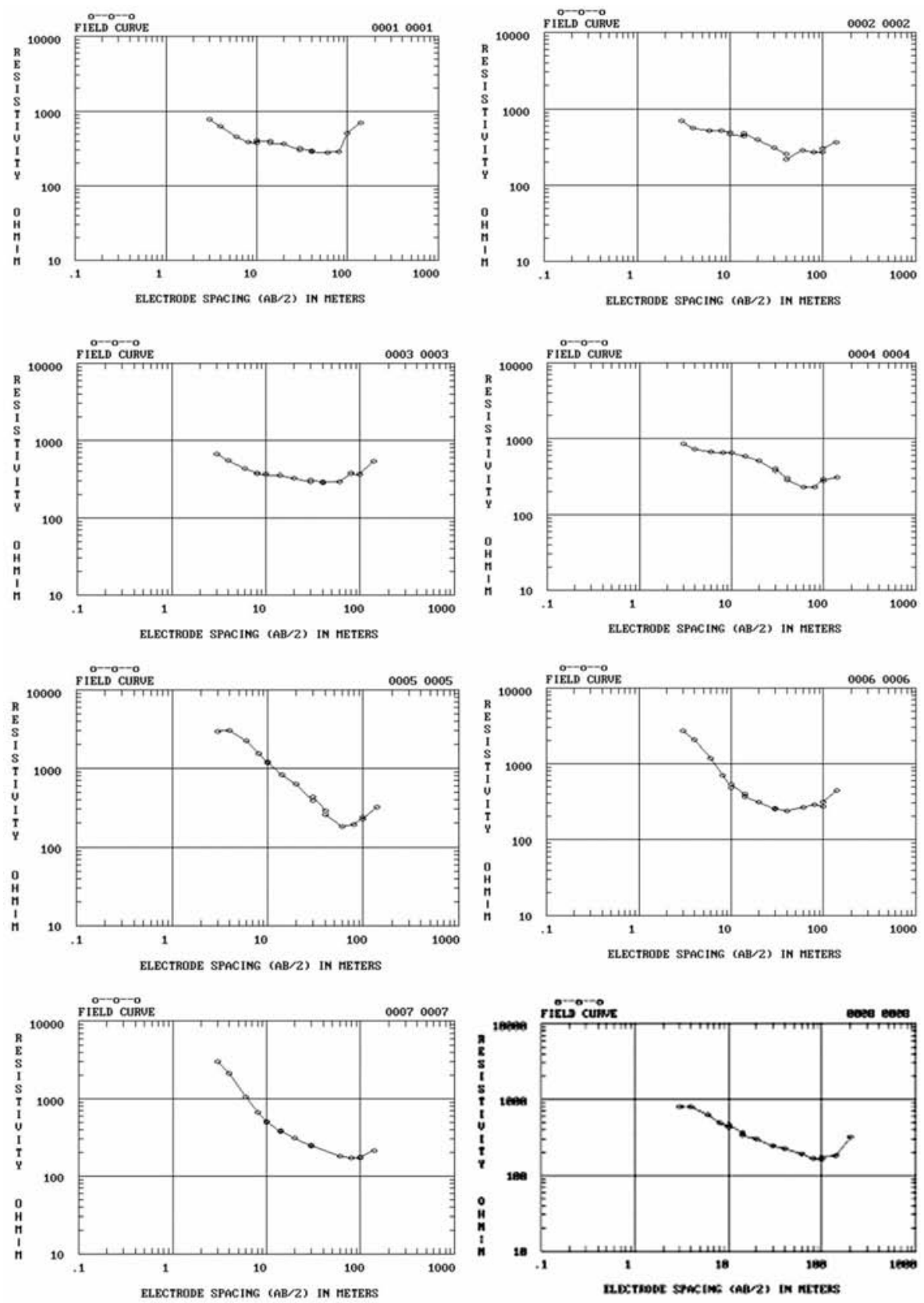

Fig. 5. Vertical electrical sounding curves VES1-VES8 along Wadi Rahjan. 

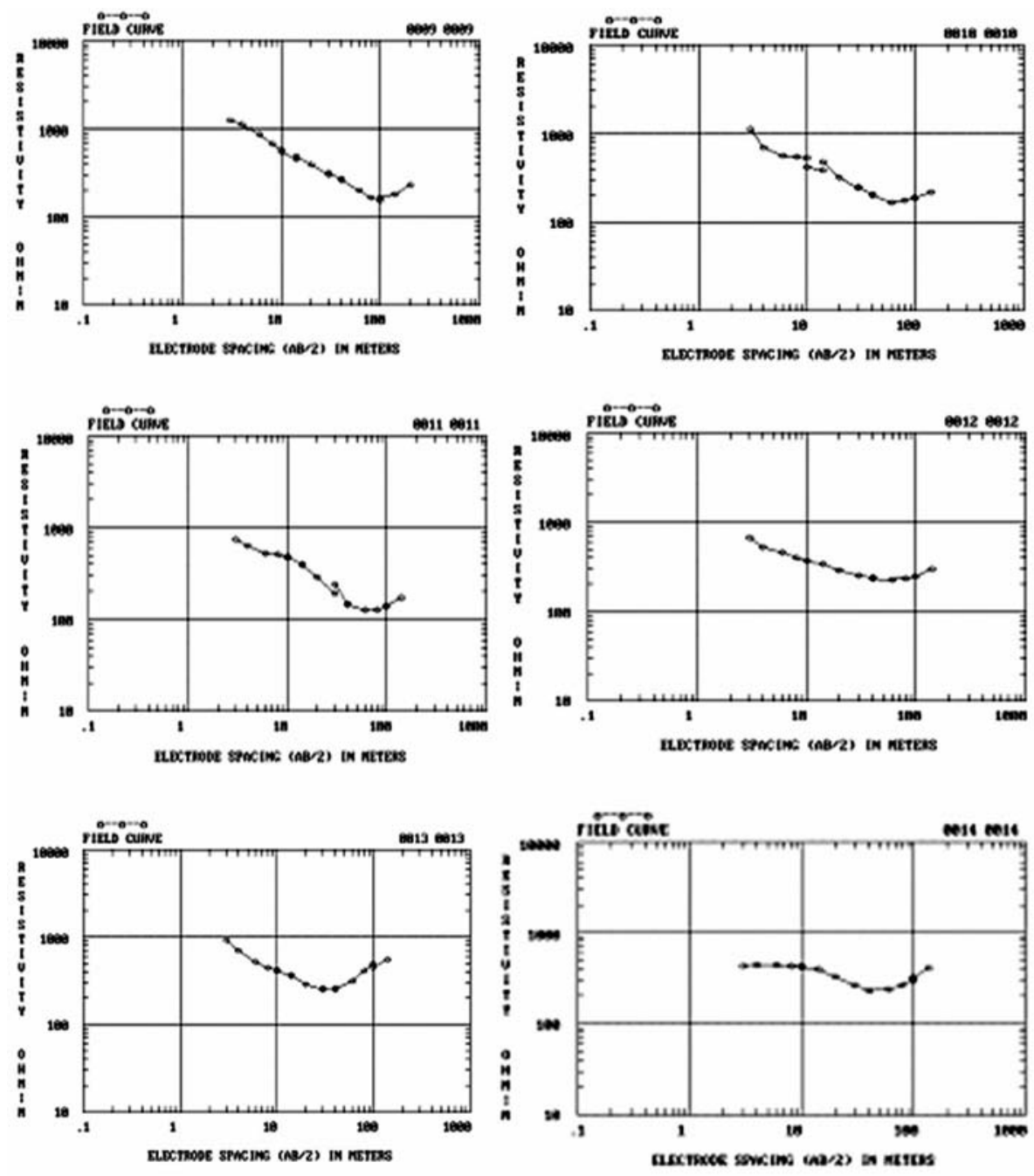

Fig. 5 (contd). Vertical electrical sounding curves VES9-VES14 along Wadi Rahjan. 


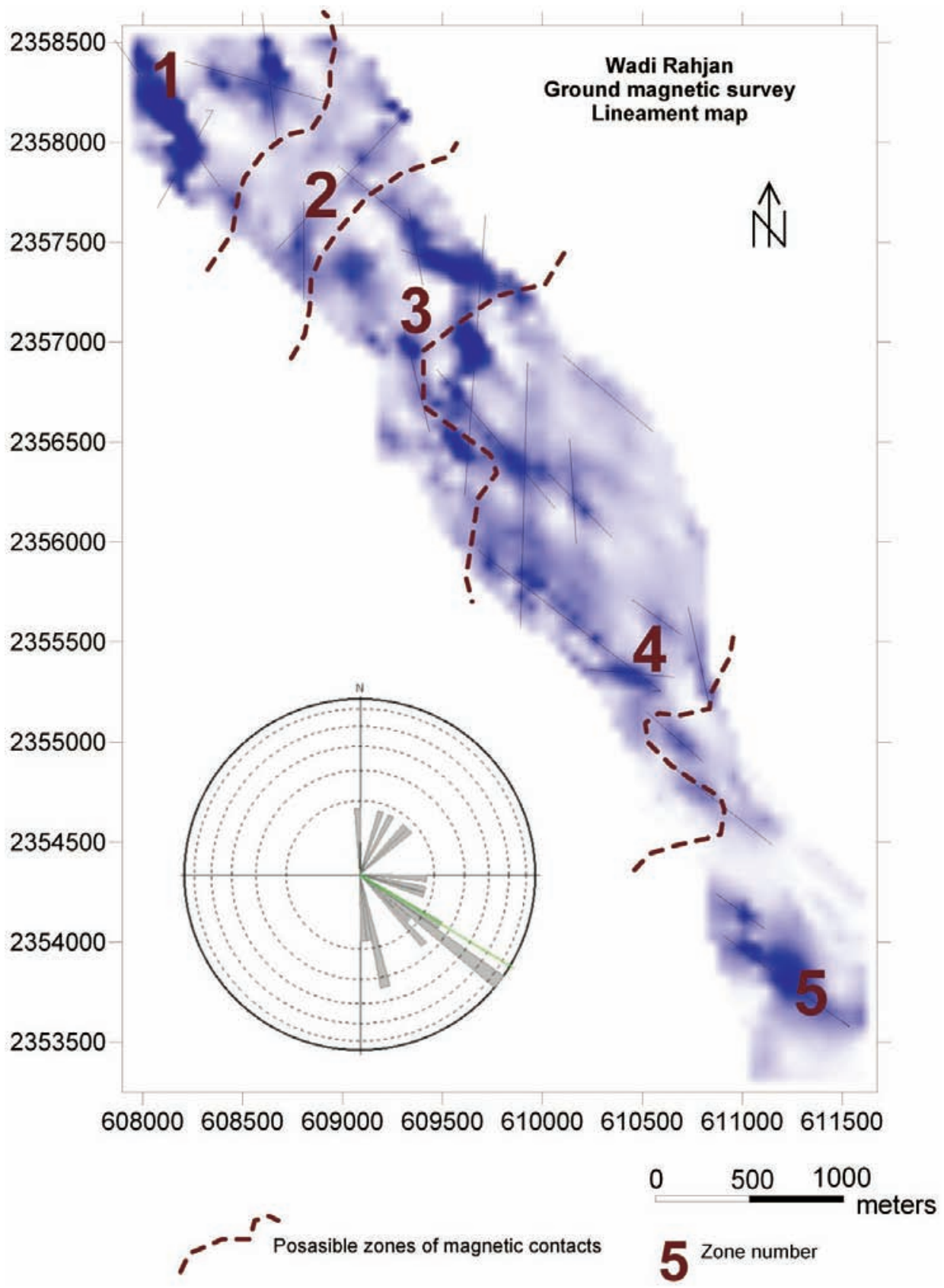

Fig. 6. Image map of the total intensity magnetic map and rose diagram showing the possible magnetic contacts and the distribution of posted contacts. 

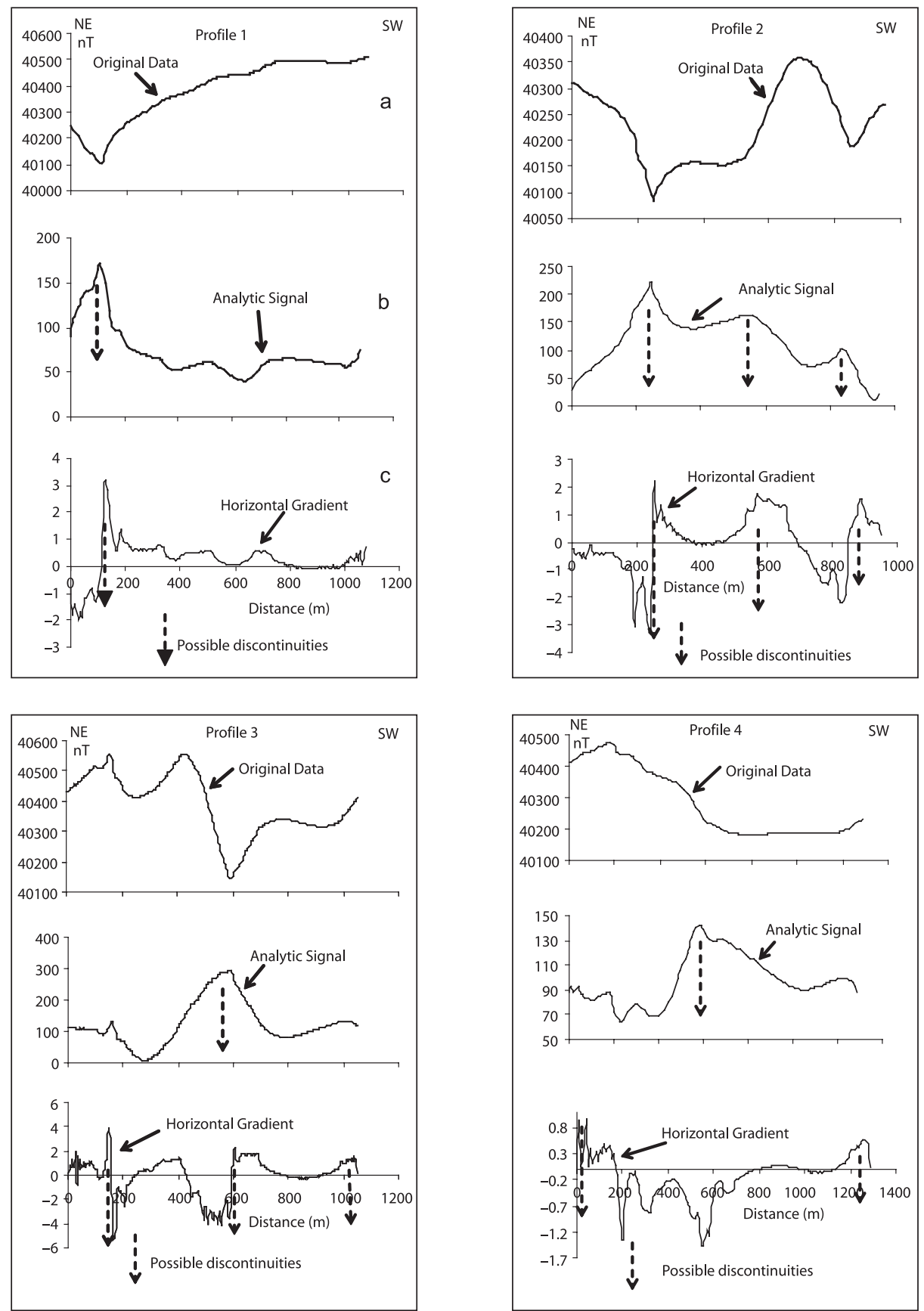

Fig. 7. Analytic signal and horizontal gradient of total magnetic intensity field along profiles $1,2,3$ and 4. 

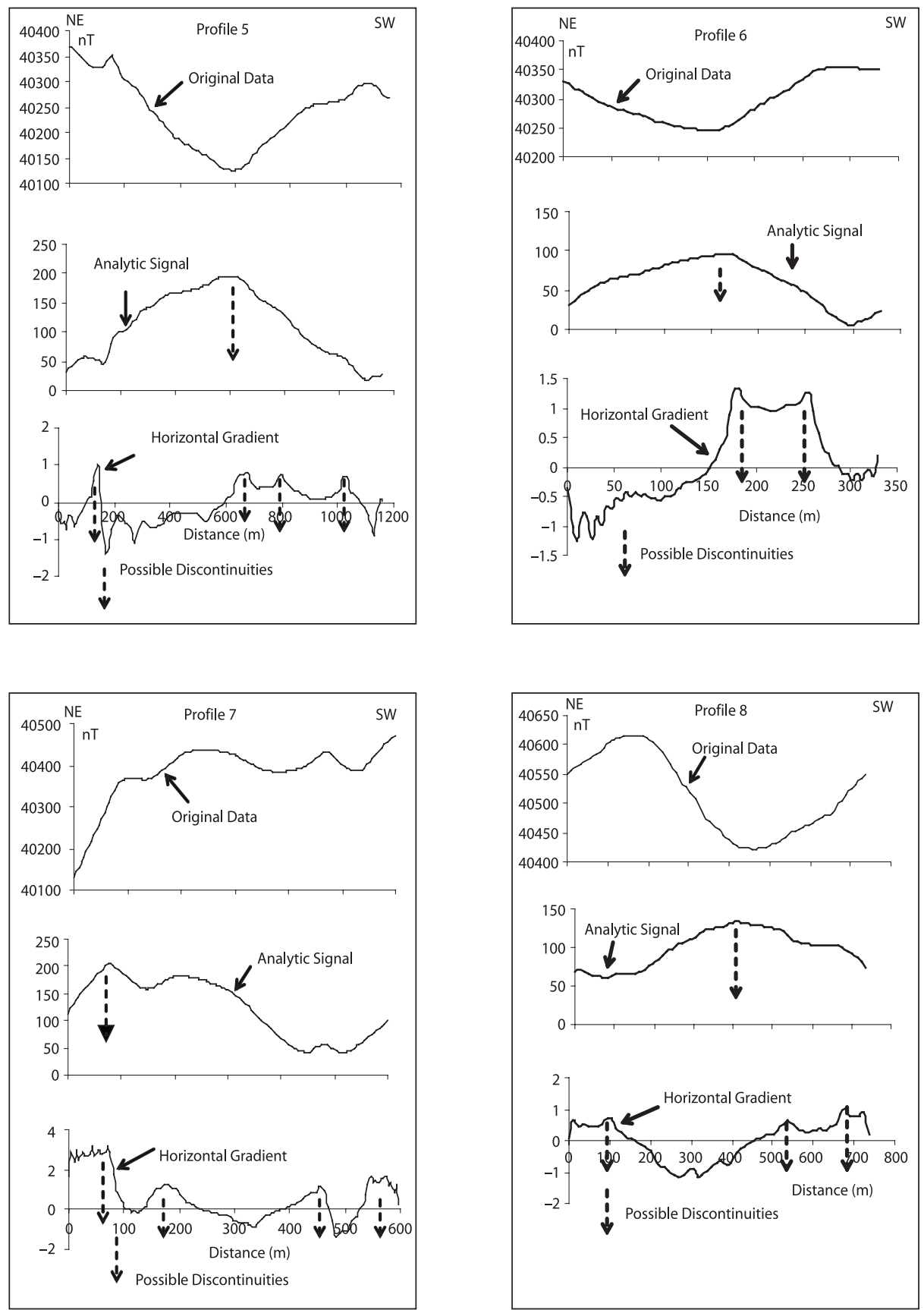

Fig. 7 (contd). Analytic signal and horizontal gradient of total magnetic intensity field along profiles 5, 6, 7 and 8 . 


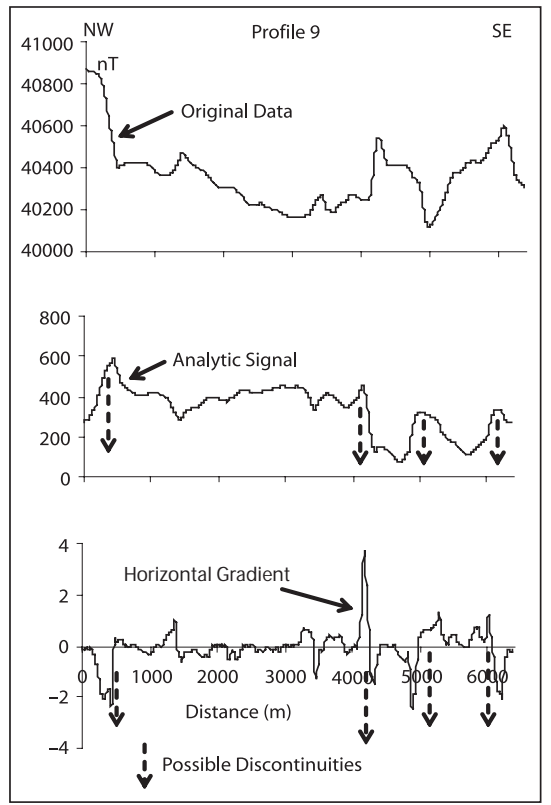

Fig. 7 (contd). Analytic signal and horizontal gradient of total magnetic intensity field along profile 9.

from a complex potential. The complex field can be computed in the frequency domain in which the real part is the horizontal derivative and the imaginary part is the vertical derivative. The only assumption beside a uniform magnetization is that the cross-sections of all source bodies are considered polygons of finite or infinite extension. The field curve is differentiated with respect to $x, T(x)$ (horizontal derivative). This derivative curve can be considered as being due to thin magnetized sheets surrounding the source bodies. Then, the derivative data $T(x)$ is Fourier transformed $F(\omega)$ to yields a new spectrum $\widetilde{F}(\omega)$ as Nabighian (1972)

$$
\begin{aligned}
& \Delta M(x) \rightarrow T(x)=\frac{\partial(\Delta M)}{\partial x} \rightarrow F(\omega) \\
& \tilde{F}(\omega)=\left\{\begin{array}{cc}
2 F(\omega) & \omega>0 \\
F(\omega) & \omega=0 \rightarrow T(x)-i H(x) \text { where } H(x)=\frac{\partial(\Delta M)}{\partial z} \\
0 & \omega<0
\end{array}\right.
\end{aligned}
$$

For a single sheet

$$
\begin{aligned}
& (\text { Amplitude })^{2}=a(x)=T^{2}+H^{2}=\frac{\left(2 k F_{e} c \sin d\right)^{2}}{z^{2}+x^{2}} \\
& c=1-\cos ^{2} i \sin ^{2} d \quad \text { for total field anomaly }
\end{aligned}
$$


where $\Delta M$ is the magnetic anomaly, $x$ is the horizontal axis, $z$ is the vertical axis positively downward, $k$ is the susceptibility contrast, $F_{e}$ is the earth's magnetic field and $d$ is the angle between magnetic north and positive $x$.

The spectrum $\widetilde{F}(\omega)$ is causal in the frequency domain and is defined only for positive values argument and nil otherwise. As it is known, the Fourier transform of such causal functions has the property in which their real and imaginary parts are Hilbert transform of each other. In this paper case, the real part of the inverse Fourier transform of $\widetilde{F}(\omega)$ yields to the original input function $T(x)$ whereas the imaginary part yields to the vertical derivative of the field profile $H(x)$. Consider $T(x)-i H(x)$ is the inverse Fourier transform of $\widetilde{F}(\omega)$ which is an analytic function, as shown in Nabighian (1972), everywhere except at the corners of each polygon where the single poles are located. The amplitude of the analytic signal or any of its horizontal derivatives, for the case of a single of infinite sheet, is a bell-shaped symmetric function maximizing and located exactly over the top of magnetized sheet causative body. Nabighian (1972) showed the width of the amplitude is related to the depth of the causative body. Nabighian (1984) derived the relationship between the horizontal and vertical derivatives for the 3-D case. In the concept of 2-D case, the horizontal and vertical derivatives are Hilbert transforms of each other and so can be extended to 3-D case (Debeglia and Corpel, 1997). The amplitude of the analytic signal is defined as the square root of the squared sum of the vertical and the two horizontal first derivatives of the magnetic filed (Roest et al., 1992).

The interpretation of the analytic signal amplitude shape is independent of the directions of the earth's magnetic field and magnetization vector (Debeglia and Corpel, 1997). Furthermore, it is independent of the dip of the contact and also of magnetization value. Roest and Pilkington (1993) showed that the depth estimations can be implemented without any prior knowledge of the magnetic properties of the causative sources.

The horizontal gradient technique has been utilized in the potential field methods. Phillips (2000) utilized the amplitude of this technique on a reducedto-pole magnetic field of the pseudogravity transformation of the magnetic field. The steepest horizontal gradient of magnetic anomaly tends to overlie the edge of a body where the horizontal gradient tends to have maxima located over the edge of magnetic sources (Blakely, 1995). Hence, the horizontal gradient technique can be used to accurately locate the tops of isolated contacts from the reduced-to-pole magnetic field (Phillips, 2000). Contacts with non-vertical dips will result in the horizontal locations of the maximum amplitude that are down dip from the actual locations (Grauch and Cordell, 1987). The horizontal gradient method which has been used in this study is based on the algorithm that has been described by Gunn (1975) in which a function, in my case magnetic anomaly 
$\Delta M(x)$, has the Fourier transform $F(\omega), \Delta M^{n}(x)$ has the Fourier transform $(i \omega)^{n} \Delta M(\omega)$ (Hsu, 1970, p. 87). Therefore, the filter to calculate the $n$th horizontal derivative in the $x$ or $y$ directions has

$$
(i u)^{n} \text { or }(i v)^{n}
$$

where $u$ and $v$ are the wave number in the $x$ and $y$ directions, $n$ is the order of derivative which was assigned as 1 in the present study. He showed that the spectral representation of magnetic field represents that the mathematical expressions describing this field is the result of convolution of factors that depend on the geometry of the source body, the physical properties of the causative body and the type the observed field.

The depth estimation to the magnetic sources was determined using Euler deconvolution method because the observed magnetic field, $\Delta M$, and its two derivatives are evaluated at all points $(x, z)$ to provide the unknown magnetic source location $\left(x_{0}, z_{0}\right)$ (Reid et al., 1990). This technique is used because it is both a depth estimator and boundary finder (Reid et al., 1990, Stavrev, 1997, Stavrev et al., 2003, Al-Garni, 2004 and 2005). The 2-D Euler's homogeneity equation is defined as (Reid et al., 1990, Al-Garni, 2004 and 2005)

$$
\left(x-x_{0}\right) \frac{d(\Delta M)}{d x}+\left(z-z_{0}\right) \frac{d(\Delta M)}{d z}=N(B-\Delta M)
$$

$B$ the base level of the observed magnetic field, and

$N$ the source geometry (structural index).

The appropriate choice value of $\mathrm{N}$ leads to the right position $\left(x_{0}, z_{0}\right)$ of the causative magnetic source. In this paper, I used $N=0.5$ because the only structures that were expected in Wadi Rahjan are contacts and dikes.

\section{Resistivity Data Processing}

Two mainly processing techniques are used in the present study:

Zohdy (1989) and Davis (1979). The first method is utilized where the reduced field data are processed using the inversion technique developed by Zohdy (1989) to obtain an equivalent-layer model, n-layered model (Fig. 8). The results of the n-layer models of the different soundings are then used to construct the subsurface resistivity contour section along Wadi Rahjan (Fig. 9). The contoured values represent the logarithmic values of the resistivity.

The second method is also applied to all sounding field data where this method is based on an initial layer model Davis (1979), which was approximated from the previous method, Zohdy (1989). Figure 10 shows a sample of the final 


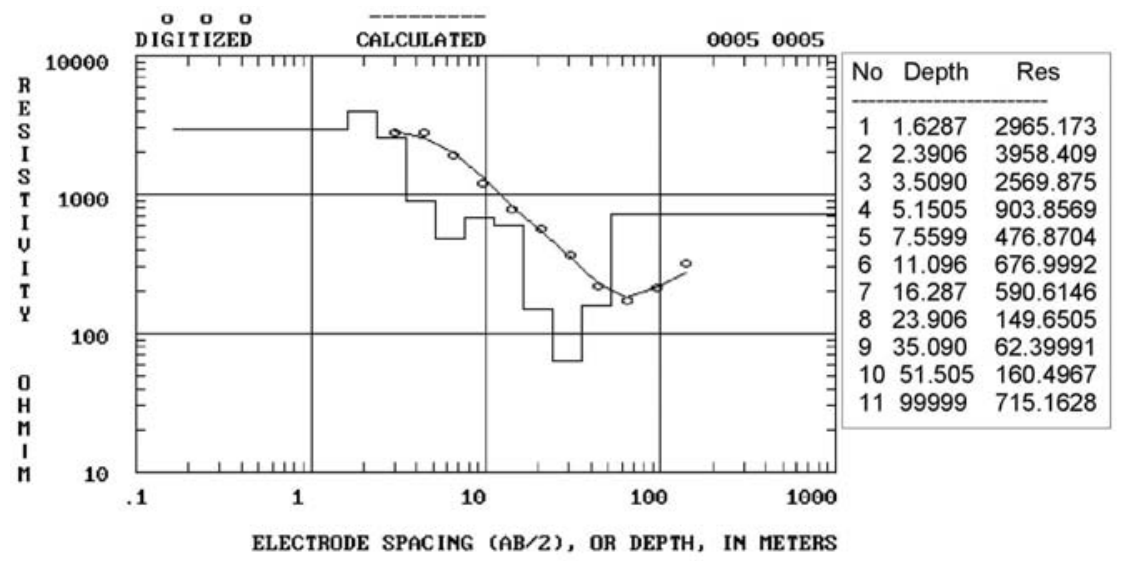

Fig. 8. Interpreted vertical electrical sounding curve using Zohdy method.

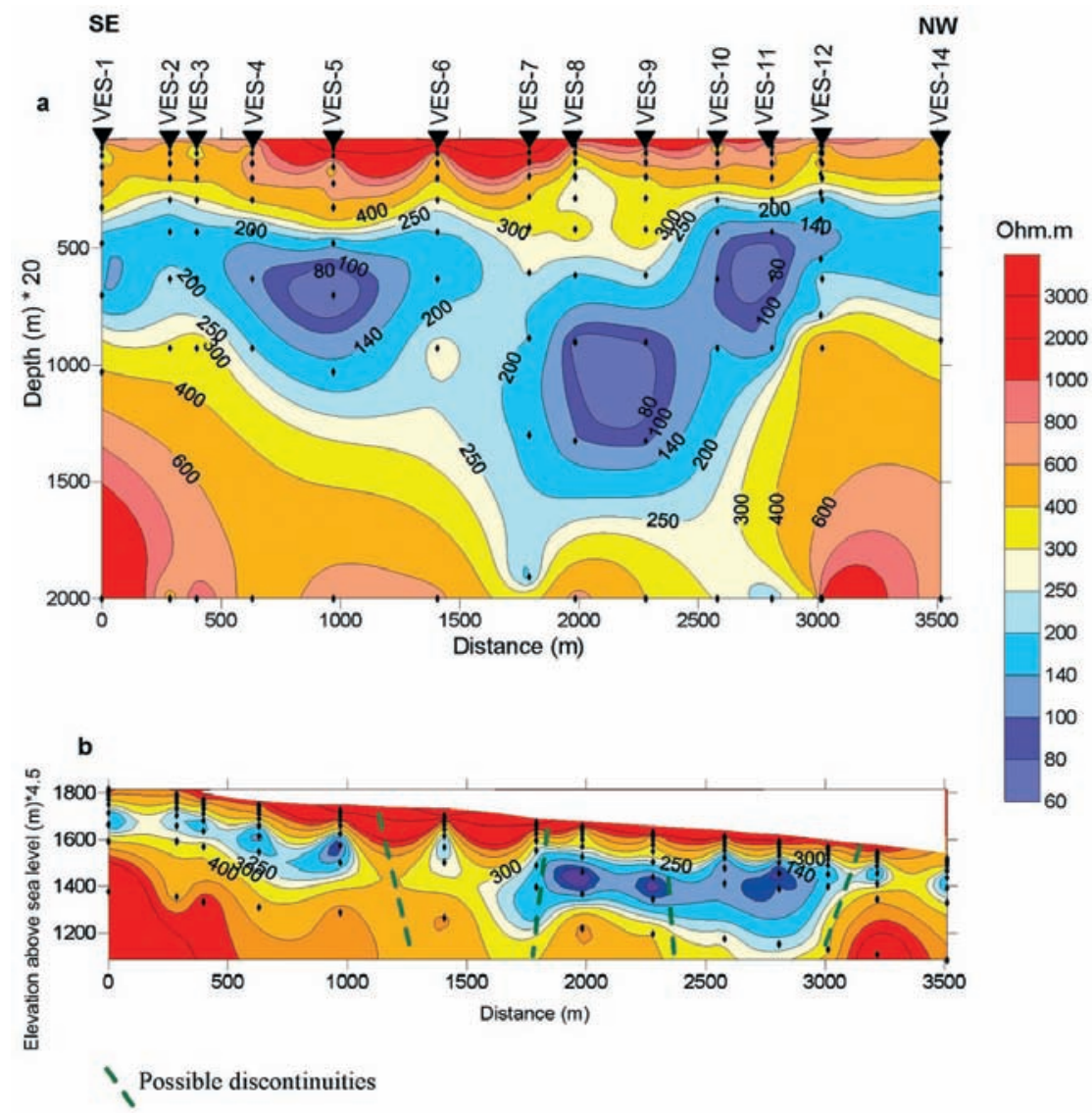

Fig. 9. a) Geoelectric cross-section before topographic correction using Zohdy method, b) Geoelectric cross-section after topographic correction. 


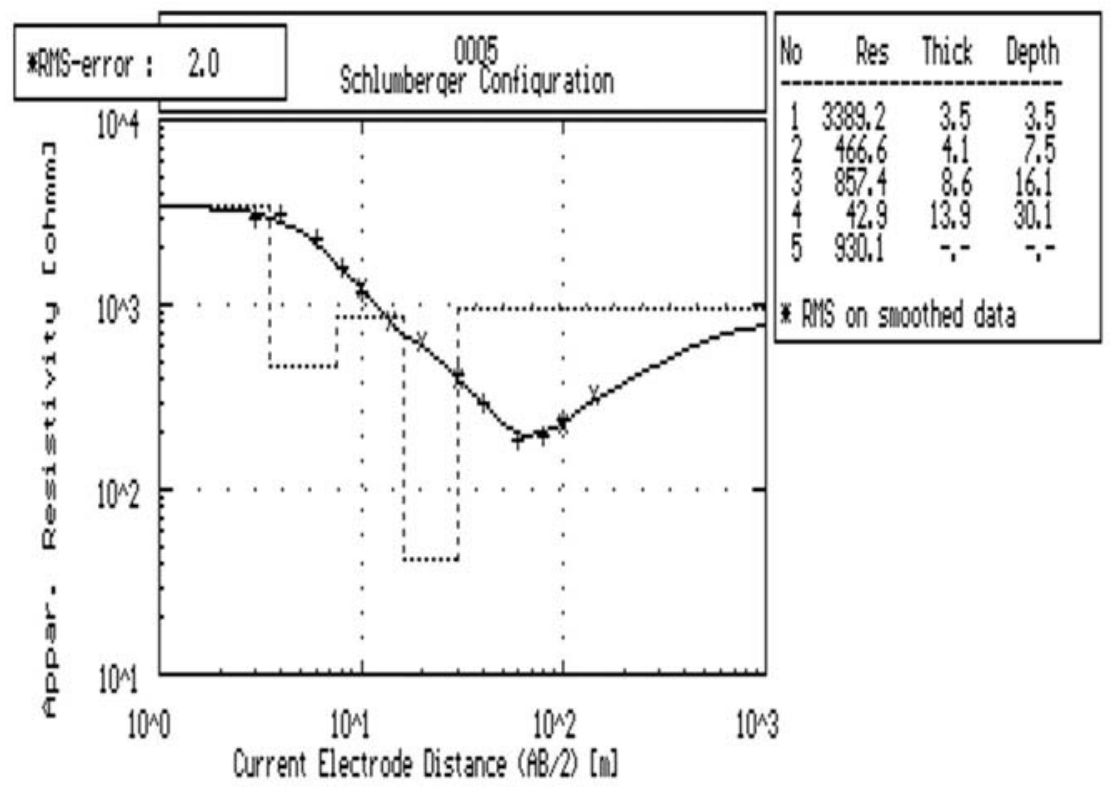

Fig. 10. Interpreted vertical electrical sounding curves using Davis method.

result using Davis's method (1979) and the corresponding depth and resistivity of each layer in this model. The resulted layering models of the different soundings were then used to construct the subsurface resistivity geoelectric layering section along Wadi Rahjan (Fig. 11).

\section{Interpretation of Geophysical Data}

\section{Magnetic Data Interpretation}

The analytic and horizontal gradient techniques are applied to the selected nine profiles of the total magnetic field intensity data (Fig. 4 and 7). The analytic signal technique is applied to profiles taken across the wadi that correlates directly to magnetic contacts. The location of these contacts is represented by down arrows on each profile. However, the analytic signal applied along the profile taken along the wadi indicates the presence of, most probably, dikes, based on the field observation on both sides of the wadi, where at least the peak at a distance approximately $4300 \mathrm{~m}$ from the start point is related to an exposed dike on both sides. There are, may be, at least four dikes/discontinuities along wadi Rahjan, 250, 4200, 5000 and $5700 \mathrm{~m}$ from the start point of the profile (NW). The major peak that is pronounced in all SE-NW profiles may be related to the major fault that might have caused the generation of this wadi. 

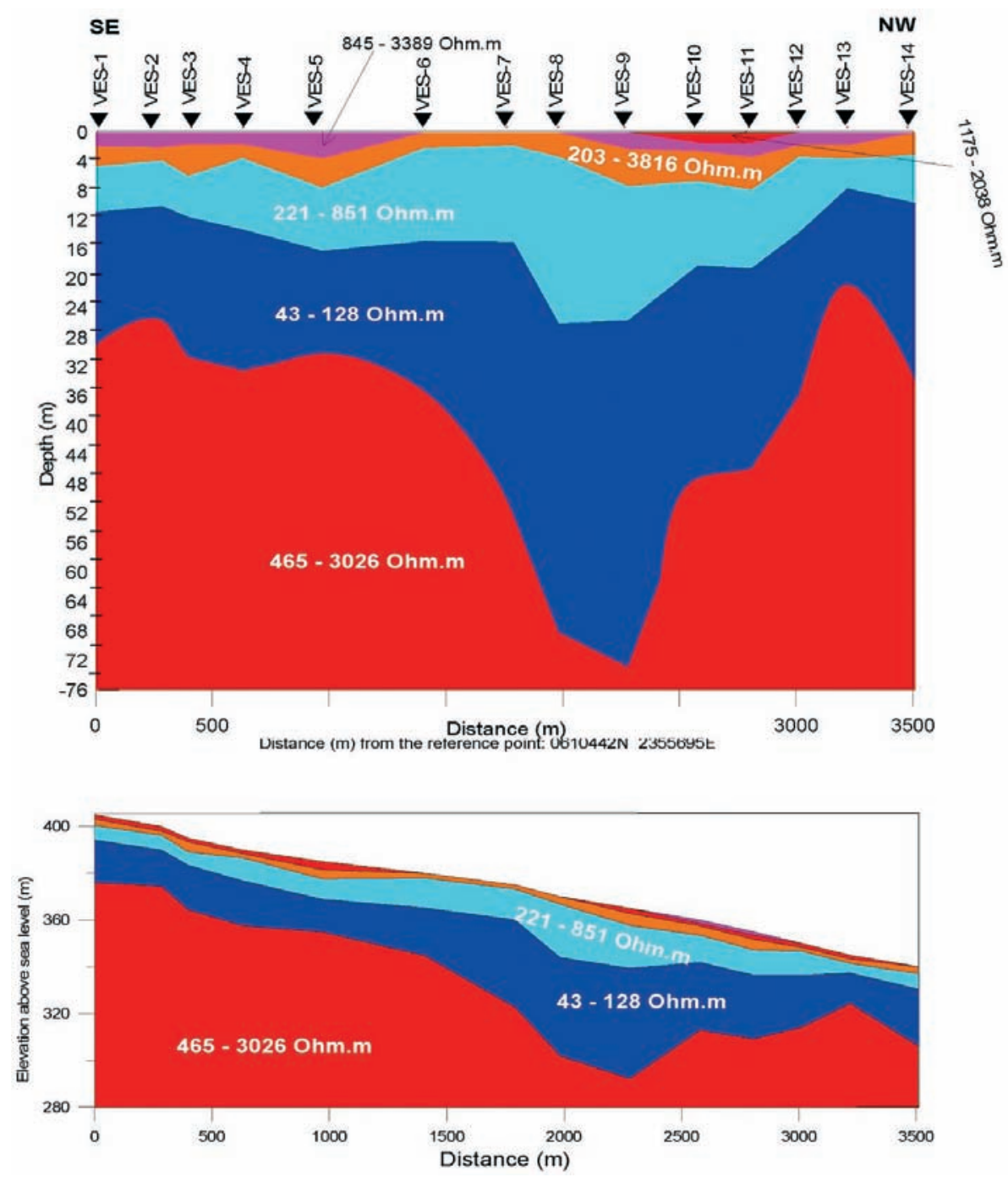

Fig. 11. a) Geoelectric cross-section before topographic correction using Davis method, b) Geoelectric cross-section after topographic correction.

The horizontal gradient technique is applied to profiles taken across the wadi correlates also to magnetic contacts. Profile 9 shows considerable peaks which may be also related to dikes/discontinuities. The contacts can be seen also along each profile taken across the Wadi, which are also represented by down arrows. However, profiles taken along the wadi show that the wadi has been affected by dikes/magnetic contacts such as faults. There are four major dikes/magnetic contacts shown at about 250, 4200, 5000 and $5700 \mathrm{~m}$ from the start point of the profile (NW). 
The Euler deconvolution method is applied to profile 9, along Wadi Rahjan, to investigate the magnetic source rock depth (Fig. 12). The solution of Euler deconvolution technique is presented as clusters, which are related to the depth of causative body. The result of this technique reveals the existence of magnetic discontinuities near or at the distances that I have mentioned earlier using analytic signal and horizontal gradient. Furthermore, the solution of Euler deconvolution technique shows that the dikes may be associated with magnetic contacts, which agreed with the other methods of interpretation.

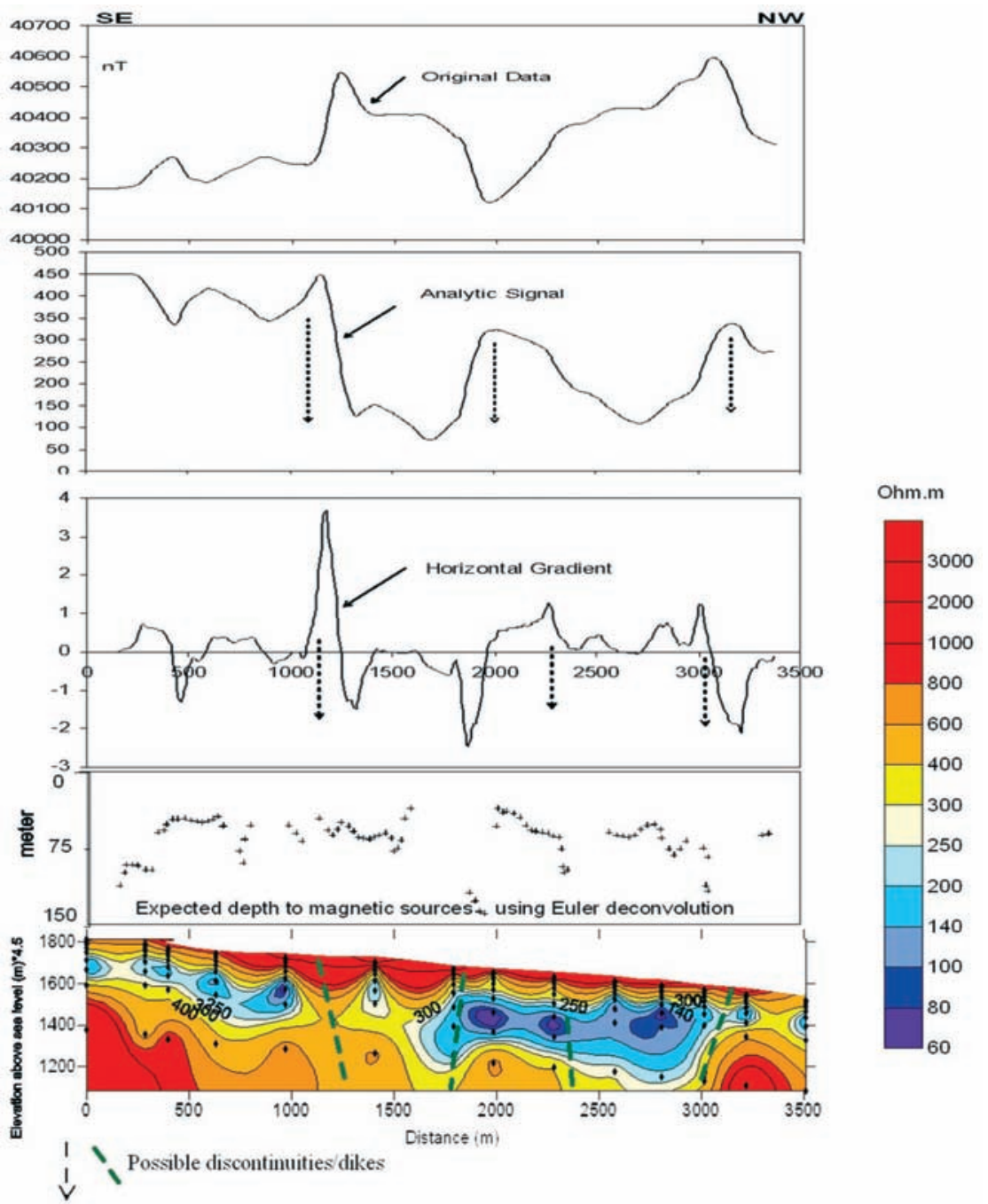

Fig. 12. a) Magnetic field curve along electrical sounding profile. b) Analytic signal technique of the total magnetic intensity field, and c) Horizontal gradient technique of the total magnetic intensity field. 


\section{Resistivity Data Interpretation}

The resistivity and depth values of the total 14 sounding obtained from Zohdy method (Zohdy, 1989) are used to construct a cross section along Wadi Rahjan (Fig. 9). This figure shows the geoelectric cross-section before and after taking into account the elevation of each VES. This correction was done in order to mimic the reality which gives more reasonable interpretation.

The southern part of the studied wadi shows a relatively high resistivity of dry rock formation. This part of wadi is separated from the northern part, which shows relatively low resistivity, by certain structure such as contacts (fault or dike). The relatively low resistivity in the northern part of the wadi may be attributed to a considerable thickness of alluvium. The observed discontinuity in resistivity contour lines may be attributed to NE-SW structural trends. This structure clearly controls the distribution of the groundwater along wadi Rahjan. The resistivity values of water-bearing-layer range from about 43-128 Ohm.m.

Davis method (Davis, 1979) applied to all resistivity soundings shows that the geoelectric section can be classified into three main layers, where the surface layer is not considered as a layer (Fig. 11). The first layer has a resistivity range from 221-851 Ohm.m, which may represent unsaturated to dry alluvium layer. Beneath this layer is a layer with resistivity range from 43-128 Ohm.m, which may represent saturated alluvium. The last layer with a resistivity range from 465-3026 Ohm.m represents the basement rocks.

\section{Discussion and Conclusion}

Electrical resistivity and ground magnetic survey methods are mainly used to identify the saturated zone and the main structures that control the groundwater flow and its impact on wadi Nu'man, where AinZubaidah is cutting through, respectively. Ground magnetic survey shows that the wadi most probably has been cut by major four dikes trending NW-SE and may be some minor contacts, such as faults in the same direction. However, a major fault is shown along the wadi trending NE-SW where the wadi was formed. Moreover, there may be minor faults associated with it and attained the same direction. Vertical electrical sounding delineates the possible water accumulation along wadi Rahjan from upstream (SE) to downstream (NW). Geoelectric section shows three major dikes which agree with the magnetic interpretation (Fig. 12).

The structure that has been determined in Wadi Rahjan has a great impact on the distribution of groundwater from upstream to downstream. These dikes act as barriers and control the groundwater flow from upstream to downstream side. The last dike at the downstream side shows a great impact on groundwater flow to Wadi Nu'man acting as a barrier. The integration between ground magnetic 
survey and DC resistivity method provides better understanding of the possible location of structure and the saturated zones at the conducted wadi. Therefore, there may be a possible supply of groundwater if the wadi is continuously recharged in order to increase the groundwater level and then flow to wadi Nu'man.

\section{Acknowledgment}

The author would like to thank Dr. M. M. Gobashy and Dr. H. I. E. Hassanein of the department of geophysics, King Abdulaziz University and anonymous reviewers for the comments and suggestions on the manuscript. The author also would like to thank the staff members of the department of geophysics, King Abdulaziz University for their help in the field.

$$
\begin{aligned}
& \text { References } \\
& \text { المكي، محمد طاهر. (r اع ( هـ) كتاب التاريخ القويم لمكة وبيت الله الكريم، الجزء السادس، الطبعة الأولى. }
\end{aligned}
$$

Al-Garni, M.A. (2004) Schlumberger sounding and magnetic survey in Wadi Al-Damm, Makkah Al-Mukarramah, Saudi Arabia, Journal of Petroleum and Minning Engineering, 7: 45-60.

Al-Garni, M.A. (2005) Application of magnetic and electrical geophysical methods in the exploration of groundwater resources of Wadi Malakan, Journal of King Abdulaziz University: Earth Sciences, 16: 67-93.

Blakely, R.J. (1995) Potential Theory in Gravity and Magnetic Applications, Cambridge Univ. Press.

Davis, P.A. (1979) Interpretation of Resistivity Sounding Data: Computer Programs for Solution to the Forward and Inverse Problems, Information circular 17, Minnesota Geological Survey, 1633 Eustis St, St. Paul, MN 55108.

Debeglia, N. and Corpel, J. (1997) Automatic 3-D interpretation of potential field data using analytic signal derivatives, Geophysics, 62: 87-96.

Grauch, V.J.S. and Cordell, L. (1987) Limitations on determining density or magnetic boundaries from the horizontal gradient of gravity or pseudogravity data, Geophysics, 52: 118121.

Gunn, P.J. (1975) Linear transformations of gravity and magnetic fields, Geophysical Prospecting, 23: 300-312.

Hsu, H.P. (1970) Fourier Analysis, Simon and Schuster, New York.

Moore, T.A. and Al-Rehaili, M.H. (1989) Geologic map of Makkah quadrangle, sheet 21D, Kingdom of Saudi Arabia, DGMR, Geoscience Map GM-107C, 1:250,000 scale.

Nabighian, M.N. (1972) The analytic signal of two-dimensional magnetic bodies with polygonal cross section: its properties and use for automated anomaly interpretation, Geophysics, 39: 507-517.

Nabighian, M.N. (1984) Towards a three-dimensional automatic interpretation of potential field data via generalized Hilbert transforms: fundamental relations, Geophysics, 49: 780-786.

Phillips, J.D. (2000) Locating magnetic contacts: a comparison of the horizontal gradient, analytic signal, and local wavenumber methods, SEG Expanded Abstract. 
Roest, W.R., Verhoef, J. and Pilkington, M. (1992) Magnetic interpretation using 3-D analytic signal, Geophysics, 57: 116-125

Reid, A.B., Allsop, J.M., Granser, H., Millet, A.J. and Somerton, I.W. (1990) Magnetic interpretation in the three dimensions using Euler deconvolution, Geophysics, 55: 80-91.

Roest, W.R. and Pilkington, M. (1993) Identifying remnant magnetization effects in magnetic data, Geophysics, 58: 653-659.

Smith, J.W. (1980) Reconnaissance Geologic Map of AT Ta'if quadrangle, sheet 21/40C, Kingdom of Saudi Arabia.

Stavrev, P.Y. (1997) Euler deconvolution using differential similarity transformations of gravity and magnetic anomalies, Geophys. Prosp., 45 (2): 207-246.

Stavrev, P.Y., Gerovska, D. and Araüzo-Bravo, M.J. (2003) Euler deconvolution of magnetic anomalies over the basaltic bodies in northern Bulgaria, Annual, 46, part 2, Geology and Geophysics, Sofia, 2003, 403-407.

Zohdy, A.A. (1989) A new method for the automatic interpretation of Schlumberger and Wenner sounding curves, Geophysics, 54: 245-253. 


\title{
دراسة وجود المياه الجوفية في وادي رهجان، واحتمالية إسهامها في

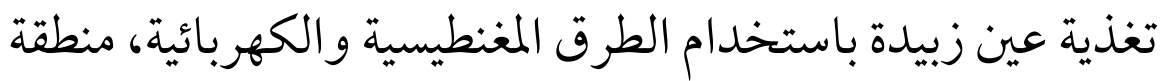 مكة المكرمة، المملكة العربية السعودية المعرية
}

\author{
منصور عبداللّه القرني \\ قسم الجيوفيزياء، كلية علوم الأرض، جامعة الملك عبدالعزيز

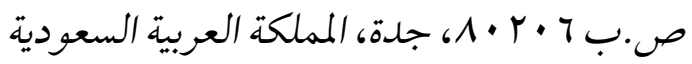

المستخلص. لقد تم إنجاز المسح المغنطيسي الأرضي والمسح الكهربائي

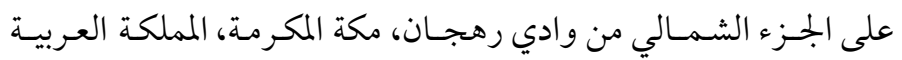

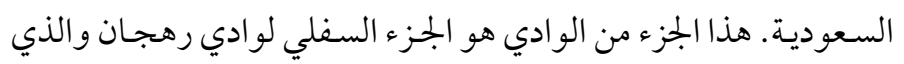

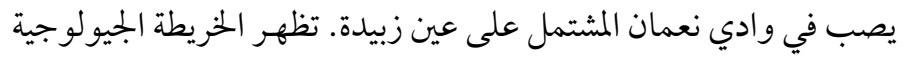

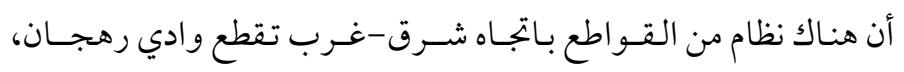

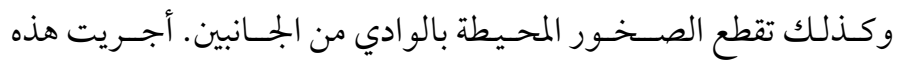

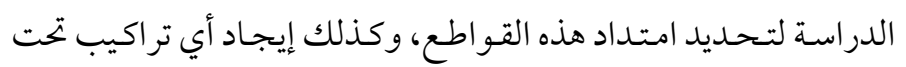

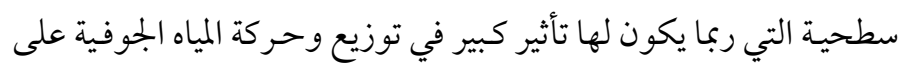

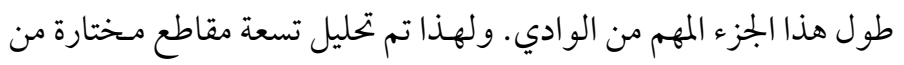
خريطة المسح المغنطيسي الأرضي لهذه الدراسة. تم تحليل هذه البيانات

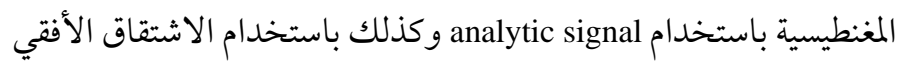
.horizontal gradient

أظهرت هذه الدراسة أن هناك على الأقل أربعة متغيرات في الخاصية

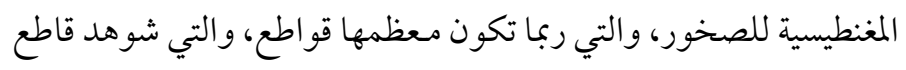

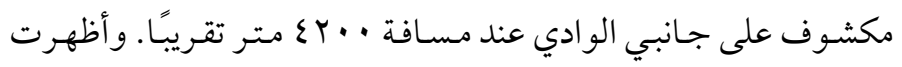

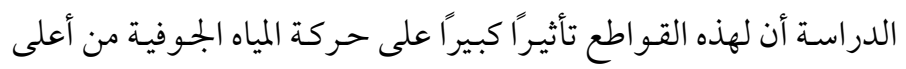

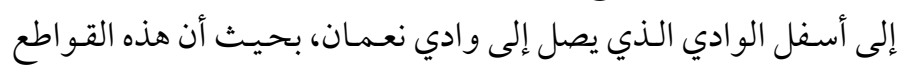
ربما تعمل على إعاقة حركة المياه الجوفية من أعلى الو ادي إلى أسفله. 
Schlum- استخدمت الدراسة أيضًا السبر الكهربائي بطريقة شلمبر جير berger صخور القاعدة وتحديد أي احتمالية وجود تجمعات من المياه الجوفية. أكدت هذه الدراسـة كذلك على أن القو اطع لها تأثير على حركة المياه

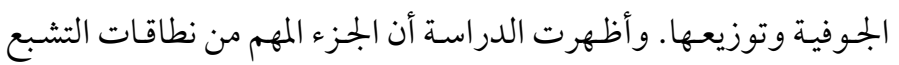
يوجـد في أسفل المجرى عند جنوب القاطع الذي يمنع جزئيًا حركة الميـاه

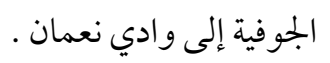

